\title{
Comunicação
}

[Communication]

\section{Efeito metafilático do zinco injetável sobre parâmetros metabólicos e oxidativos de ovelhas no pós-parto imediato}

\author{
[Metaphylactic effect of injectable zinc on metabolic and oxidative parameters of \\ sheep in the immediate postpartum]
}

\author{
J.F.X. Rocha ${ }^{1}$, A.R. Aires ${ }^{1}$, F.C. Mendes ${ }^{2}$, F.L. Pivoto ${ }^{2}$, C. Amaral ${ }^{2}$, V.D. Torbitz ${ }^{2}$, R. Moresco ${ }^{2}$, M.A. \\ Gonçalves $^{2}$, E.M.M. Flores ${ }^{2}$, R.S. Sousa ${ }^{3}$, E.L. Ortolani ${ }^{3}$, R.X. Rocha ${ }^{4}$, M.L.R. Leal ${ }^{2}$ \\ ${ }^{1}$ Universidade do Oeste de Santa Catarina - UNOESC - São Miguel do Oeste, SC \\ ${ }^{2}$ Universidade Federal de Santa Maria - UFSM - Santa Maria, RS \\ ${ }^{3}$ Universidade de São Paulo - USP - São Paulo, SP \\ ${ }^{4}$ Médico veterinário autônomo
}

O zinco (Zn) é um mineral amplamente utilizado na suplementação animal. Esse elemento é encontrado em pequenas concentrações no organismo dos seres vivos e apresenta baixa toxicidade, podendo ser administrado tanto na forma oral quanto na parenteral, quando se busca um efeito metafilático. Esse micromineral tem como uma das suas principais funções a manutenção do metabolismo oxidativo, pois está presente na enzima superóxido dismutase $(\mathrm{Cu}$ ZnSOD), que atua como uma das primeiras defesas do sistema antioxidante (Hambidge et al., 2010).

No metabolismo energético, as funções do zinco estão associadas à insulina, aumentando sua sensibilidade na ligação com seus receptores no pâncreas e em outros órgãos, podendo incrementar a entrada da glicose para o interior da célula (Marreiro et al., 2004). Além disso, o zinco está relacionado ao fator de crescimento semelhante à insulina tipo 1 (IGF-1), hormônio que, na espécie ovina, apresenta uma importante função durante o período gestacional, pois atua no crescimento feto-placenta, além de realizar ações mitogênicas e metabólicas (Feng Dong et al., 2005).

A atenção ao metabolismo energético é imprescindível na espécie ovina, principalmente no período do pré-parto. Nesse momento, pode ocorrer uma série de problemas relacionados ao manejo nutricional dos animais, acarretando um declínio ou aumento na condição corporal das fêmeas gestantes (Ribeiro, 2002). No terço final da gestação, ou até mesmo após o parto, pode ocorrer o balanço energético negativo (BEN) em ovelhas e, consequentemente, o aumento nas concentrações de corpos cetônicos, sobretudo o ß- hidroxibutirato (BHB), afetando diretamente o metabolismo da glicose desses animais, o que pode causar desordens metabólicas severas (Khaled, 2011).

Tendo em vista que ovelhas em final de gestação e no pós-parto imediato são submetidas a um maior desafio metabólico e oxidativo e que o zinco exerce importantes funções relacionadas a tais condições, o objetivo deste estudo foi avaliar o efeito do zinco parenteral sobre o perfil energético e oxidativo de ovelhas no pós-parto imediato. Foram utilizadas 26 ovelhas da raça Texel, criadas extensivamente, com idade entre três e quatro anos e condição corporal 3,0. Estas foram submetidas a protocolo de sincronização de estro durante sete dias, com o auxílio de pessários vaginais impregnados de progesterona. Após a retirada, realizou-se aplicação de prostaglandina, e as ovelhas foram colocadas em contato com reprodutores andrologicamente testados. Após 45 dias da retirada dos carneiros, foi realizada a confirmação de prenhes por meio de ultrassonografia. Foram utilizadas somente

Recebido em 29 de agosto 2016 
ovelhas com gestação simples, distribuídas em dois grupos experimentais: grupo tratado (GT; $\mathrm{n}=13$ ), animais que receberam $100 \mathrm{mg}$ de edetato de zinco SC (2mL) 15 dias antes da data prevista do parto; e grupo controle ( $\mathrm{GC} ; \mathrm{n}=13)$, animais que receberam $2 \mathrm{~mL}$ de solução fisiológica $\mathrm{SC}$ na mesma data que o GT. Os animais dos dois grupos foram avaliados clinicamente mediante realização de ausculta pulmonar e cardíaca, da mensuração da temperatura corporal e da visualização da coloração das mucosas aparentes. Nenhum animal apresentou alteração dos parâmetros fisiológicos ou clínicos durante todo o período experimental.

O zinco utilizado foi o edetato de zinco (50mg/mL- Biogenesis Bagó, Argentina). Essa fórmula permite a utilização do zinco puro ligado ao ácido etilenodiaminotetracético na forma injetável, evitando a interação de microminerais no rúmen/intestino e, assim, aumentando sua biodisponibilidade.

Foram coletadas amostras de sangue 15 dias antes da data prevista do parto, para exclusão de problemas metabólicos prévios, e imediatamente após o parto, para avaliação do efeito do edetato de zinco. As coletas foram obtidas mediante punção da veia jugular externa, utilizando-se o sistema Vacutainer ${ }^{\circledR}$. Foram coletados $20 \mathrm{~mL}$ de sangue em tubo siliconado sem anticoagulante. Após a coleta, o sangue foi centrifugado, e o soro armazenado em tubos tipo Eppendorf e congelado em freezer a $-80^{\circ} \mathrm{C}$ até o momento das análises. Nas amostras de soro, foram avaliados os valores de IGF-1, de frutosamina, de colesterol, de triglicerídeos e do índice de estresse oxidativo (OSi), sendo este obtido por meio da mensuração do total de antioxidantes.

Outra amostra foi coletada em tubos heparinizados para avaliação dos teores de zinco no sangue mediante o uso da técnica de espectrofotometria de emissão óptica com plasma indutivamente acoplado (ICP OES) em espectrômetro Perkin Elmer (Optima 4300 DV).

Entre os parâmetros sanguíneos avaliados, o IGF-1 foi determinado por eletroquimioluminescência em equipamento Immulite 1 (Siemens, modelo 1000, São Paulo, $\mathrm{SP}$, Brasil). Os parâmetros bioquímicos e o perfil oxidativo foram mensurados em aparelho automático bioquímico (Cobas Mira - Roche Diagnostics, Montclair, EUA). O índice de estresse oxidativo (OSI) foi realizado mediante determinação do total de antioxidantes TAC e do total de oxidantes TOS (Erel, 2004), mediante a fórmula: [(TOS $\mu \mathrm{mol} / \mathrm{L}) /(\mathrm{TAC} \mu \mathrm{molTrolox}$ equivalente/L) x 100].

Foram considerados para a análise estatística dois grupos experimentais (GT e GC), avaliandose o efeito do edetato de zinco apenas no pósparto. Os dados foram submetidos à análise de variância (ANOVA), seguida pelo teste t a 5\% de significância. As análises estatísticas foram realizadas com o aplicativo SAS, versão 9.0 (Statistical., 2002) O protocolo experimental foi aprovado pela Comissão de Ética em Uso de Animais da UFSM (047/2013).

As concentrações de zinco na dieta foram de $0,05 \mathrm{mg} / \mathrm{g}$ e na água $>0,1 \mathrm{mg} / \mathrm{L}$. Não foi observado efeito da administração do zinco entre os grupos nas variáveis frutosamina, colesterol, triglicerídeos e IGF-1 ( $\mathrm{P}>0,05)$. Entretanto, o colesterol apresentou maiores valores numéricos no GT em relação ao GC. Em relação aos valores relacionados ao índice de estresse oxidativo e às concentrações de zinco no sangue, não houve diferença no índice entre os grupos durante o período experimental $(\mathrm{P}>0,05)$ (Tab. 1).

Tabela 1. Valores médios e erro-padrão de parâmetros metabólicos e oxidativos de ovelhas no pós-parto imediato

\begin{tabular}{lcccc}
\multirow{2}{*}{ Variáveis } & \multicolumn{2}{c}{ Tratamentos } & \multirow{2}{*}{ Erro-padrão } & \multirow{2}{*}{ Valor de P } \\
\cline { 2 - 3 } & Controle & Tratado & & \\
\hline Frutosamina $(\mu \mathrm{mol} / \mathrm{L})$ & $255,36 \mathrm{a}$ & $253,04 \mathrm{a}$ & 15,24 & 0,91 \\
Triglicerídeos $(\mathrm{mg} / \mathrm{dL})$ & $26,15 \mathrm{a}$ & $26,90 \mathrm{a}$ & 1,87 & 0,81 \\
Colesterol $(\mathrm{mg} / \mathrm{dL})$ & $76,15 \mathrm{a}$ & $80,73 \mathrm{a}$ & 3,08 & 0,30 \\
Zinco/sangue $(\mu / \mathrm{g})$ & $2,51 \mathrm{a}$ & $2,43 \mathrm{a}$ & 0,06 & 0,40 \\
OSI $(\mu \mathrm{mol} / \mathrm{Trolox}$ equivalent/L) & $65,00 \mathrm{a}$ & $65,40 \mathrm{a}$ & 10,64 & 0,32 \\
IGF-1 $(\mathrm{ng} / \mathrm{mL})$ & 173,13 & 164,53 & 16,13 & 0,71 \\
\hline
\end{tabular}

Médias seguidas de letras distintas na linha denotam diferença entre grupos. Nível de significância de 5\%. 
Em pequenos ruminantes, especialmente próximo ao parto, observa-se maior incidência de distúrbios metabólicos que podem culminar em risco de vida para a ovelha e o feto (Ribeiro, 2002). A ocorrência dessas enfermidades no periparto de ovelhas está diretamente relacionada à tentativa dessa fêmea de equilibrar a deficiência de energia mobilizando suas reservas corporais para compensar a baixa ingesta de alimento comum nessa época (Khaled, 2011). Esperava-se, neste estudo, que o zinco atuasse sobre o metabolismo energético, já que ele está relacionado diretamente com a insulina e seus receptores.

No entanto, é importante ressaltar que as ovelhas utilizadas neste estudo provavelmente não passaram por desafio metabólico acentuado, visto que a condição corporal média dos animais era 3 (escala de 1 a 5; Russel et al., 1969) e que não houve aumento nos valores de triglicerídeos, descartando um quadro de mobilização lipídica nos animais experimentais. Outros parâmetros relacionados ao metabolismo energético, como o IGF-1 e o colesterol, também não apresentaram diferenças entre os grupos experimentais.

Em estudo realizado com fêmeas caprinas, Rodrigues (2001) observou uma redução no consumo de matéria seca de até $16 \%$ no periparto desses animais. Resultado como este não foi observado no presente estudo, pois não houve variação nos valores do colesterol sérico, o qual está relacionado com o consumo alimentar de ruminantes (Guretzky et al., 2006). Em relação à avaliação do edetato de zinco sob o índice de estresse oxidativo, Pivoto et al. (2015) observaram redução no estresse oxidativo em cordeiros infectados por parasitos gastrointestinais e suplementados com o edetato de zinco SC. Em situações de distúrbios metabólicos em ovelhas com expressiva mobilização lipídica, pode ocorrer aumento acentuado na produção de espécies reativas ao oxigênio (ERO) e ao nitrogênio (ERN), com consequente exaustão do sistema antioxidante e ocorrência de estresse oxidativo (EO). O estresse oxidativo pode causar danos aos carboidratos, às proteínas e ao DNA (Khaled, 2011). Uma vez que não houve desafio metabólico e, portanto, não houve desequilíbrio entre o sistema oxidante/antioxidante, o zinco não foi utilizado como cofator para aumentar a atividade da superóxido dismutase, que é a primeira barreira enzimática antioxidante do organismo.

A absorção do zinco após sua suplementação ocorre principalmente no intestino delgado. Nos seres vivos, depois de o zinco ser absorvido, ele vai para a circulação sanguínea e cerca de $55 \%$ desse mineral se liga à albumina e a aminoácidos, sendo o resto estocado em diversos órgãos. Para avaliação da concentração desse mineral no organismo, recomenda-se correlacionar os valores sanguíneos com o que é encontrado em tecidos, como o fígado, e, quando possível, com enzimas dependentes de Zn, como a metalotioneina (Hambidge et al., 2010). É provável que o zinco tenha se ligado à metalotioneina, uma vez que não houve demanda desse mineral no metabolismo energético e oxidativo.

Além disso, os teores de zinco na dieta foram em torno de $50 \mathrm{mg} / \mathrm{kg}$, o que ultrapassou os valores recomendados pelo NRC (Nutrient..., 2007) $(30 \mathrm{mg} / \mathrm{kg})$. Embora o zinco na dieta e o administrado aos animais tenham sido de fontes distintas, e a absorção provavelmente tenha sido realizada em quantidades diferentes, é provável que o zinco excedente possa ter sido estocado em órgãos específicos, principalmente o fígado (Pal et al., 2010). Conclui-se que o zinco injetável não influencia o perfil enérgico e o índice de estresse oxidativo no pós-parto de ovelhas com reduzido desafio metabólico.

Palavras-chave: ovinos, metabolismo energético, perfil oxidativo, edetato de zinco

\begin{abstract}
The aim of this study was to evaluate a new source of injectable organic zinc (zinc edetate) on the energy and oxidative profile in sheep during the immediate postpartum period. Twenty-six Texel breed animals were previously identified and divided into two experimental groups: the treated group $(T G ; n=13)$ that comprised the animals that received a subcutaneous (SC) injection of $100 \mathrm{mg}$ of zinc edetate $(2 \mathrm{~mL})$ fifteen days before the parturition expected date and the control group $(C G ; n=13)$ that comprised the animals that received $2 \mathrm{~mL}$ of physiological solution at the same date of TG. Blood samples were
\end{abstract}


collected on the parturition day for the assessment of serum fructosamine, cholesterol and triglycerides, insulin-like growth factor type 1 (IGF-1), the oxidative stress index (OSi) and blood zinc concentration. In addition to these parameters, the measurement of zinc was made in food given to the animals. There was no difference in metabolic parameters and OSi between the experimental groups $(P>0.05)$, as well as in blood zinc concentrations $(P>0.05)$. The parenteral zinc edentate does not change the energy and oxidative profile of sheep in immediate postpartum.

Keywords: sheep, energy metabolism, oxidative profile, zinc edetate

\section{REFERÊNCIAS}

EREL, O.A novel automated method to measure total antioxidant response against potent free radical reactions. Clin. Biochem., v.37, p.112119, 2004.

FENG DONG, F.; FORD, S.P.; FANG, C.X. et al. Maternal nutrient restriction during early to mid gestation up-regulates cardiac insulin-like growth factor (IGF) receptors associated with enlarged ventricular size in fetal sheep. Growth Horm. IGF Res., v.15, p.291-299, 2005.

GURETZKY, N.A.J.; CARLSON, D.B.; GARRETT, J.E.; DRACKLEY, J.K. Lipid metabolite profiles and milk production for Holstein and Jersey cows fed rumen-protected choline during the periparturient period. J. Dairy Sci., v.89, p.188-200, 2006.

HAMBIDGE, M.K.; MILLER, L.V.; WESTCOTT, J.E. et al. Zinc bioavailability and homeostasis. Am. J. Clin. Nutr., v.91, p.14781483, 2010.

KHALED, M.; AL-QUDAH Oxidant and antioxidant profile of hyperketonemic ewes affected by pregnancy toxemia. Vet. Clin. Path., v.40/41, p.60-65, 2011.

MARREIRO, D.; GELONEZE, B.; TAMBASCIA, M.A. et al. Participação do zinco na resistência à insulina. Arq. Bras. Endocrinol. Metab., v.48, p.234-239, 2004.

NUTRIENT requirements of sheep. 6.ed. Washington: National Academy Press, 2007.
PALL, D.T.; GOWDA, N.K.; PRASAD, C.S. et al. Effect of copper- and zinc- methionine supplementation on bioavailability, mineral status and tissue concentrations of copper and zinc in ewes. J. Trace Elem. Med. Biol., v.24, p.89-94, 2010.

PIVOTO, F.L.; TORBITZ, V.D.; AIRES, A.R. et al. Oxidative stress by Haemonchus contortus in lambs: Influence of treatment with zinc edentate. Res. Vet. Sci., v.102, p.22-24, 2015.

RIBEIRO, L.A.O. Perdas reprodutivas em ovinos no Rio Grande do Sul determinadas pelas condições nutricionais e de manejo no encarneiramento e na gestação. 2002. 106f. Tese (Doutorado em Ciências Veterinárias) Universidade Federal do Rio Grande do Sul, Porto Alegre, RS.

RODRIGUES, C.A.F. Efeito do nível de energia líquida da dieta sobre o desempenho e perfil de ácidos graxos não esterificados de cabras leiteiras com diferentes condições corporais no período de transição. 2001. 87f. Dissertação (Mestrado em Nutrição de Ruminantes) Universidade Federal de Viçosa, Viçosa, MG.

RUSSEL, A.J.F.; DONEY, J.M.; GUNN, R.G. Subjective assessment of body fat in live sheep. J. Agric. Sci., v.72, p.451-454, 1969.

STATISTICAL analysis system. Version 9.0. Cary: SAS Institute, 2002. 